\title{
A CRITICAL REVIEW ON TRACTION CONTROL SYSTEM
}

\author{
VIRENDRA PATEL \& RASHMI RAY
}

ITER, Siksha 'O'Anusandhan Deemed to be University, Bhubaneswar, Odisha, India

\begin{abstract}
This paper shares an investigation of vehicle footing control and examines its significance in interstate mechanization. A vigorous control technique is intended for slip control, which thus controls the footing. It is indicated how traction control can be utilized to fulfill diverse goals of vehicle control. The significance of footing is additionally accentuated by contrasting its execution with inactive controllers in a recreation contemplates in which a motivation like breeze unsettling influence is presented. The similar investigation demonstrates that the framework under footing control is steady within the sight of outside unsettling influences, though the framework under latent control may end up temperamental within the sight of outer aggravations. The course control technique with fluffy control calculation and sliding mode control calculation can be successfully adjusted to the confused street surface conditions.
\end{abstract}

KEYWORDS: Vehicle Footing, Fluffy Control Calculation \& Sliding Mode Control Calculation

Received: Apr 17, 2019; Accepted: May 07, 2019; Published: Jun 25, 2019; Paper Id.: IJMPERDJUN2019195

\section{INTRODUCTION}

Vehicle footing control framework assumes an imperative job in electronic solidness control (ESC) framework. So as to enhance the vehicle footing execution on low $\mu$ surface street and boost the longitudinal contact coefficient, TCS is utilized to control the slip proportion inside the scope of ideal slip proportion by directing motor yield torque or braking weight.

As of late, numerous hypothetical investigations dependent on wheel slip rate are led all around the globe. In literary works [1, 2], the rationale edge controller is acknowledged by managing the braking weight. It is anything but difficult to execute this strategy; however the improvement cycles for various vehicles are long.

Traction-control is actually a management program in automo-software to raise safety and stability of autos. Well known auto management systems like antilock brake system (ABS), anti-slip regulation (ASR), along with also electronic stability program (ESP) can be employed in internal combustion motor automobiles (ICVs). Traction-control produces equilibrium when cornering in icy or damp roads, also stops the car or truck signals until the automobile could proceed minus the brakes slipping when hastening to a surface that minimizes engine outcome out of swerving. A differential doesn't usefully disperse the torque after there is a wheel slipping. The ability has been directly applied perhaps maybe never and then also to the wheel that was to the wheel that has grip. An electric traction control method averts a wheel out of slipping by employing a brake allowing the metering to use capability. The controller strategy is compiled by means of a system that quotes the street surface state and also a control which regulate the wheel slide at values. Management plans are suggested in the literature predicated on sliding mode controls, fuzzy approaches, and also logic to restrain wheels proceeding sliding Measure. The fact motivates handle approaches that this device is both unclear and nonlinear. Just lately, plenty of functions from this is of grip handle algorithms such as electrical vehicles $(\mathrm{EV})$ was formulated $[3,4]$. The torque production 
is true and speedy for decelerating and accelerating. The inverter ensures the torque controller of every single wheel; also it doesn't take partitioning equipment. The charge of the skate and also of this rate of every of the 4 wheels, enable the EV to use averting slippage. An efficient charge of the skate enables an increment of the vehicle's power performance. Grip management to motorcycles' applying isn't used as four-wheel vehicles on account of the price of this controller machine. BMW and also Kawasaki would be the businesses that employed ABS. BMW could be your exceptional company that's with an automatic equilibrium management (ASC) platform at the high high-torque BMW K1200R industrial version by 2007. BMW ASC averts the wheel when hastening out of slipping uncontrolled, also it prevents any reduction in unwanted compels and firmness $[5,6]$.

\section{Traction Control for Motorcycles}

In driving the motorcycle terms are if the bicycle is at flex or the rearing upward. The goal of this controller process is always to assist the motorist in rearing upward, in keeping up a charge of the motorcycle and at turn. In the two instances, this engine to the wheel's power can create the increased increasing loss in command of their bike. Rearing up happens as soon as the bike isn't in also the torque and bend is still high [6]. Within this instance, this wheel's rate is significantly higher compared to the rate of wheel. The motorist can prevent pruning upward, cutting back this blossom valve commanding the accelerator's introduction. Within this instance, the wheel is slightly closer into this center of this flex related for the wheel that's moving speedier and increasingly much by your center of this bend $[7,8]$. Inside this scenario, the motorist may lose this motorcycle's constraint. As a way to cut the rate of their wheel to prevent that, the torque should be reduced by the motorist. In the two instances, as a way to stay the same the rate of both brakes this grip control's purpose will be to decrease the torque. To do so, an estimation of the wheels' rate has to be achieved with detectors $[8,9]$.

\section{TRACTION CONTROLLER ARCHITECTURE}

The specification of this platform is its own applicability to motorcycle, over the ignition management program that is different. The torque put on the wheel might be controlled by diminishing the current into the plug or diminishing the gasoline. Since it's going to soon be displayed inside this part, whereas the latter has been accessed the prior may not be accessed without modifying the shot control. Every bicycle includes a button applied to show the motor off; the swap stops to earth the electric current flowing at the coil. The strategy integrating another button in parallel off change is modified by the platform[10]. The change is managed with means of a micro controller about the grounds of this output signal of a few detectors. At the floor, the voltage put on the spark plug has been already reported, at the cover of the figure, a dip at the heartbeat could be observed. The clip the electric recent of this spark-plug in is got in 2 manners: specifying off the cut delay in between the beginning of ignition trigger and also the intervention of this grip controller, also specifying the amount of sequential ignition sparks for the grip handle takes actions[11]. The torque is modified by the flicker levied with the grip control.

\section{PARAMETER ESTIMATION}

The precondition of slip proportion control is to gauge the ideal slip proportion precisely. The technique for assessing the ideal slip proportion depends on looking for extraordinary estimation of $\mu-\lambda$ bend ( $\mu-\lambda$ bend signifies the connection between the street grinding coefficient and the slip proportion). The connection between $\mu$ and $\lambda$ can be communicated by Kiencke demonstrate $[12,13]$. The condition for Kiencke show is as per the following: 


$$
\mu(\lambda)=30 \lambda / 1+p 1 \lambda+p 2 \lambda 2
$$

Where, $p 1$ and $p 2$ denote the parameters for different road conditions. Table 1 shows the values of $p 1$ and $p 2$ in different road surface conditions. Optimal slip ratio is available by seeking the extreme value of Kiencke model (8). Optimal slip ratio $\lambda p$ is shown as follows:

Table 1

\begin{tabular}{|c|c|}
\hline Process & Burst Time \\
\hline$p 1$ & 24 \\
\hline$p 2$ & 3 \\
\hline
\end{tabular}

$\lambda p=p 2-1 / 2$,

$\mu p(\lambda p)=30 p 1+2 p 21 / 2$

\section{EXPERIMENT AND RESULTS}

The basic simulation conditions are listed as follows:

- Target $\mathrm{p}$ Simulation Result. For validation, some typical simulations were carried out by using Matlab/Simulink software ath: straight, no steering angle input,

- Accelerator pedal opening: $100 \%$.

Case 1 (low $\mu$ slippery road surface): The relation between the opening degree of accelerator pedal and the vehicle speed. The opening degree of accelerator pedal is proportional to the vehicle speed. However, the vehicle speed ceases to increase when the opening degree reaches $90 \%$.

Case 2 ( $\mu$-jump road surface): Figure 1 shows the simulation result of the vehicle driving under a $\mu$-jump road surface condition. The phenomenon of road transition from high $\mu(\mu=0.8)$ to low $\mu(\mu=0.2)$ happens at $4 \mathrm{~s}$. It is obvious that the controller could identify the change of road conditions and the slip ratio is controlled to the new desired value [14, $15]$.

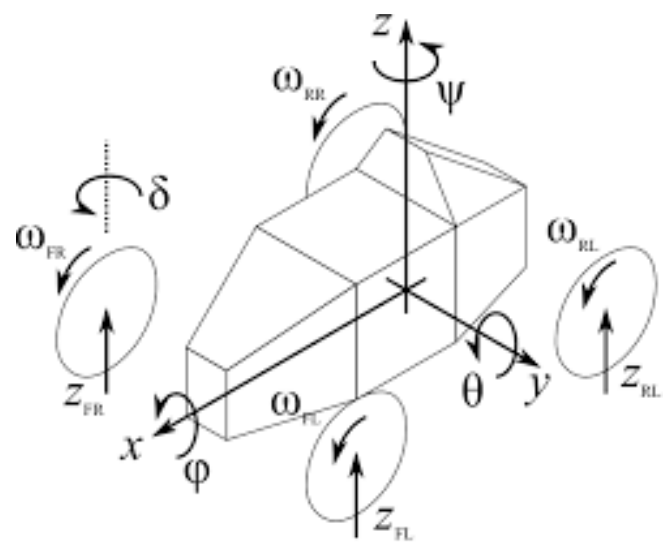

Figure 1: Vehicle Driving under a $\mu$-Jump Road Surface Condition

\section{CONCLUSIONS}

An epic footing control framework, which comprises of a motor torque controller and a weight controller, for the assessment of vehicle increasing speed and steadiness. The qualities of the TCS can be portrayed as pursues: 
- A strategy for continuous computation of ideal slip proportion is acknowledged by Variable Forgetting Factors Recursive Least Square (VFFRLS) calculation. And, after that the ideal slip proportion is considered as the ideal estimation of slip control.

- The course control technique with fluffy control calculation and sliding mode control calculation can be successfully adjusted to the confounded street surface conditions.

\section{REFERENCES}

1. Y. Yifan, Z. Jian, Z. Yang, and W. Jian, "Research and Test on Traction Control System of Distributed Driving Electric Vehicles," in Conference Proceedings Of 2017 3rd Ieee International Conference On Control Science And Systems Engineering (ICCSSE), 2017, pp. 277-280.

2. B.-R. Ke, K.-L. Lian, Y.-L. Ke, T.-H. Huang, and M. R. Mirwandhana, "Control Strategies for Improving Energy Efficiency of Train Operation and Reducing DC Traction Peak Power in Mass Rapid Transit System," in 2017 Ieee/Ias 53rd Industrial And Commercial Power Systems Technical Conference (I\&CPS), 2017.

3. Y. Sun, T. Zhang, and C. Li, "Study and Construction of Traction Control System of EMUs," in Proceedings Of The 36th Chinese Control Conference (CCC 2017), 2017, pp. 9972-9976.

4. Nireekshana, T., \& Ramesh Babu, V. (2017). Design and Fabrication of Linear Induction Motor For Traction Application. International Journal of Electrical and Electronics Engineering (IJEEE), 6(6), 1-18.

5. M. Becherif, H. S. Ramadan, M. Y. Ayad, D. Hissel, U. Desideri, and M. Antonelli, "Efficient start-up energy management via nonlinear control for eco-traction systems,” Appl. Energy, vol. 187, pp. 899-909, Feb. 2017.

6. C. Yang, C. Yang, T. Peng, X. Yang, and W. Gui, "A Fault-Injection Strategy for Traction Drive Control Systems," IEEE Trans. Ind. Electron., vol. 64, no. 7, pp. 5719-5727, Jul. 2017.

7. C. Uyulan and M. Gokasan, "Modeling, simulation and re-adhesion control of an induction motor-based railway electric traction system,” Proc. Inst. Mech. Eng. PART I-JOURNAL Syst. Control Eng., vol. 232, no. 1, pp. 3-11, Jan. 2018.

8. Abed, S. S., \& Abbas, R. F. (2016). S-Iteration for general quasi multivalued contraction mappings. Int. J. of Appl. Math. \& Stat. Sci, 5, 9-22.

9. K. Han, M. Choi, B. Lee, and S. B. Choi, "Development of a Traction Control System Using a Special Type of Sliding Mode Controller for Hybrid 4WD Vehicles," IEEE Trans. Veh. Technol., vol. 67, no. 1, pp. 264-274, Jan. 2018.

10. B. M. Majeed, X. Ge, and S. Bano, "Direct Power Control Method of Traction Converter-Inverter System with a Small DCLink Capacitor," in Railway Development, Operations, And Maintenance: Proceedings Of The First International Conference On Rail Transportation 2017 (ICRT 2017), 2018, pp. 1102-1108.

11. Sundaramurthy, A. (2017). Detection and Extraction of Brain Tumor from Magnetic Resonance (MR) Image: Review and Analysis. International Journal of Electrical and Electronics Engineering (IJEEE), 6(3), 1-8.

12. H. Kanchev, N. Hinov, B. Gilev, and B. Francois, "Modelling and Control by Neural Network of Electric Vehicle Traction System," Elektron. Ir Elektrotechnika, vol. 24, no. 3, pp. 23-28, 2018.

13. N. K. Kuznetsov, I. A. Iov, and A. A. Iov, "Investigation of efficiency of electric drive control system of excavator traction mechanism based on feedback on load," In International Conference Information Technologies In Business And Industry 2018, PTS 1-4, 2018, vol. 1015. 
14. L. Ban and C. Yang, "Simulation Experiment Platform of Electric Traction Motor Drive System Vector Control Based on Saber," in 2018 4th International Conference On Education, Management And Information Technology (ICEMIT 2018), 2018, pp. 1229-1233.

15. E. Dincel, H. Nak, S. Akkaya, M. Canevi, I. Mutlu, and M. T. Soylemez, "Robust Control of Railway Traction System,” IFAC Pap., vol. 51, no. 25, pp. 171-177, 2018.

16. Wadood, S. A., AL-Essa, H. S., \& Fadil, A. G. (2001). Causes of Teeth Extraction in Patients Attending the Outpatient Teaching Clinic in College of Dentistry, University of Basrah From 2012-2014. Microbiology, 147(Pt 4), 981-93.

17. G. El-Saady, E. A. Ebrahim, H. I. Abdul-ghaffar, Y. S. Mohamed, and A.-H. El-Sayed, "Particle-Swarm Optimization Control of Active Power Filter for Harmonic Mitigation of Hybrid Electric-Unbalanced Traction-System," in 2018 Ieee Congress On Evolutionary Computation (CEC), 2018, pp. 1879-1886.

18. N. K. Kuznetsov, I. A. Iov, and A. A. Iov, "Investigation of control system of traction electric drive with feedbacks on load," in International Conference On Mechanical Engineering, Automation And Control Systems 2017, 2018, Vol. 327.

19. O. M. Bolshunova, A. A. Korzhev, and A. M. Kamyshyan, "Adaptive control system of dump truck traction electric drive," in International Conference On Mechanical Engineering, Automation And Control Systems 2017, 2018, vol. 327. 
